Check for updates

Cite this: Chem. Sci., 2018, 9, 7787

A All publication charges for this article have been paid for by the Royal Society of Chemistry

Received 12th June 2018

Accepted 18th August 2018

DOI: $10.1039 /$ c8sc02581a

rsc.li/chemical-science

\section{Conformation of intrazeolitic choline ions and the framework topology of zeolite hosts $\uparrow$}

\author{
Juna Bae (D) and Suk Bong Hong (iD)*
}

The host-guest interactions in as-made zeolites Y, UZM-4, UZM-22, offretite, ferrierite, phillipsite, EU-12 and levyne, all of which were synthesized using choline as an organic structure-directing agent, have been investigated by a combination of different experimental techniques, including Raman, ${ }^{1} \mathrm{H}-{ }^{13} \mathrm{C} \mathrm{CP}$ MAS NMR and variable-temperature IR spectroscopies, together with theoretical calculations. The conformation of this asymmetric quaternary ammonium cation was shown to differ significantly according to the pore topology of the zeolite host and the intrazeolitic location of the organic guest molecule. Theoretical calculations using the pure-silica zeolite model reveal that among its three representative conformers (i.e., gauche, trans and trans' forms), the conformer, which was experimentally found to dominantly or exclusively exist in zeolite structures studied, always has a lower interaction energy with the surrounding zeolite framework. Our work provides the first example in which the conformation of organic structure-directing agents plays an important kinetic role in governing the phase selectivity during zeolite nucleation.

\section{Introduction}

Since the seminal work by Barrer and Denny in $1961,{ }^{1}$ both structural and compositional territories of zeolites and molecular sieves have greatly been expanded by the use of a wide variety of amines and alkylammonium ions as organic structure-directing agents (OSDAs) in their synthesis, with or without the aid of inorganic structure-directing agents (ISDAs) such as alkali metal cations, hydroxide or fluoride anions and heteroatom framework elements. ${ }^{2-5}$ The molecular size and shape, hydrophobicity/hydrophilicity and rigidity of the OSDAs employed have been known to be the key factors affecting the framework topology and composition of this industrially important class of microporous materials. With the exception of rigid polycyclic species like adamantane, on the other hand, most organic molecules possess a high degree of conformational diversity, which must also be the case of OSDAs at zeolite crystallization temperatures. Because OSDAs usually end up confined in a narrow range of conformations, it is not difficult to conjecture that the zeolite pore architecture can be altered according to the type of their conformations available under synthesis conditions. However, for all its major importance in better understanding the zeolite structure-directing phenomenon, only a few studies have examined the relationship

Center for Ordered Nanoporous Materials Synthesis, Division of Environmental Science and Engineering, POSTECH, Pohang 37673, Korea. E-mail: sbhong@ postech.ac. $\mathrm{kr}$

$\dagger$ Electronic supplementary information (ESI) available: Gel composition data, powder XRD, SEM and TGA/DTA data, Raman and multinuclear MAS NMR spectra. See DOI: $10.1039 / \mathrm{c} 8 \mathrm{sc} 02581 \mathrm{a}$ between the conformation of OSDAs, especially of those with moieties longer than the ethyl group, and the crystallized zeolite structure. ${ }^{6-8}$

Although rather simple, the choline ion $\left(\mathrm{Ch}^{+}\right.$, (2-hydroxyethyl)trimethylammonium) is known to direct the synthesis of at least 12 different structure types of zeolites when used in combination with various alkali metal and/or alkaline earth metal cations. ${ }^{2,9-12}$ It should be noted that despite the similarity in size, the structure-directing effects of the $\mathrm{Ch}^{+}$ion are considerably different from those of geometrically similar tetramethylammonium $\left(\mathrm{TMA}^{+}\right)$and tetraethyl-ammonium $\left(\mathrm{TEA}^{+}\right)$ ions, the two most widely studied OSDAs for zeolite syntheses. ${ }^{2}$ For example, $\mathrm{Ch}^{+}$gives large-pore zeolites UZM-4 (framework type $\mathrm{BPH}$ ) and UZM-22 (MEI) in the presence of $\mathrm{Li}^{+}, \mathrm{Sr}^{2+}$, or both of them, which have not been previously obtained using $\mathrm{TMA}^{+}$ or $\mathrm{TEA}^{+}{ }^{2,9}$ There are four internal bonds about which rotation can occur in its backbone ( $\mathrm{N}-\mathrm{C}-\mathrm{C}-\mathrm{O})$, allowing this $\mathrm{OH}$ groupcontaining organic cation to have a large number of possible molecular conformations. When only the rotation with respect to the $\mathrm{C}-\mathrm{C}$ bond is considered, $\mathrm{Ch}^{+}$can adopt two groups of conformations represented by the gauche and trans forms, in a broad sense. It has been repeatedly shown to exist predominantly as a gauche conformer in the solid, liquid and gas phases, mainly due to the stabilization by non-specific, electrostatic interactions between the electronegative oxygen atom of the $\mathrm{OH}$ group and the positive charge distributed over the ammonium head $\left[\left(\mathrm{CH}_{3}\right)_{3} \mathrm{~N}^{+} \mathrm{CH}_{2}\right]$ group. ${ }^{13-17}$

As shown in Fig. 1, on the other hand, the $\mathrm{OH}$ group in the trans form can be oriented in two directions without causing severe steric hindrance with the ammonium head group, unlike 


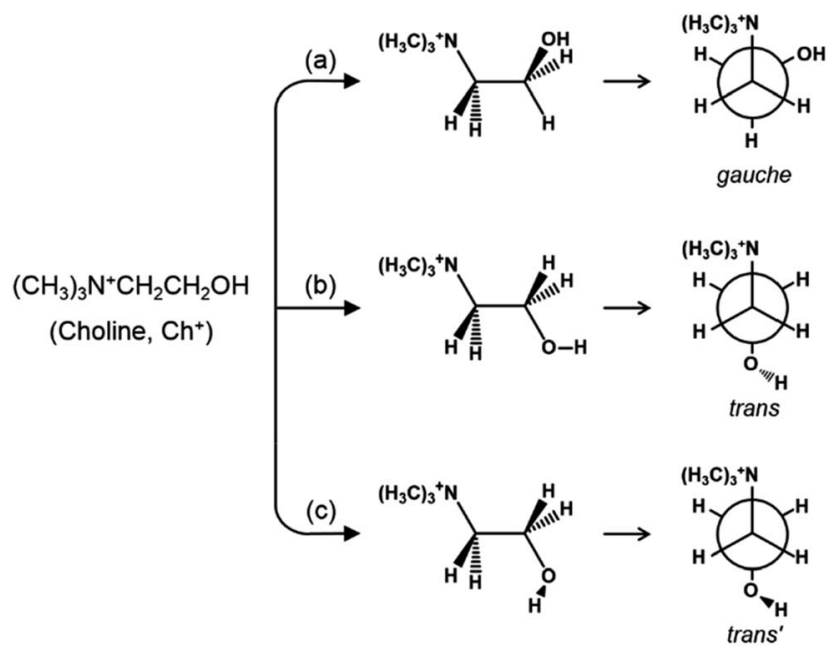

Fig. 1 The structures and Newman projections of the three representative groups of $\mathrm{Ch}^{+}$conformations: (a) gauche, (b) trans and (c) trans' conformers.

the gauche conformer. According to the theoretical work by Ashworth et al.,$^{17}$ these two groups of $\mathrm{Ch}^{+}$conformations, which have been tentatively designated as trans and trans' forms in the present study, are higher in energy by 18 and $23 \mathrm{~kJ} \mathrm{~mol}^{-1}$ than gauche $\mathrm{Ch}^{+}$in the gas phase. Clearly, a solid understanding of the host-guest interactions in zeolites containing OSDAs as guest molecules, which has long been one of our main research interests, ${ }^{\mathbf{6}, 18,19}$ is the first step in controlling the phase selectivity of crystallization. With this in mind, we have investigated such interactions occurring within a series of as-made zeolites with different framework topologies (i.e., Y (FAU), UZM-4, UZM-22, offretite (OFF), ferrierite (FER), phillipsite (PHI), EU-12 (ETL) and levyne (LEV)) synthesized using $\mathrm{Ch}^{+}$as an OSDA. Here we present their Raman, ${ }^{1} \mathrm{H}^{-13} \mathrm{C}$ CP MAS NMR and variabletemperature IR spectra in order to check whether the conformation of OSDAs is closely related to the structure type of the crystallized zeolite host. The experimental results are correlated with the relative energies of three representative $\mathrm{Ch}^{+}$ conformers in each zeolite, as well as their total stabilization energies, that have been calculated using the mixed quantummechanical and semi-empirical ONIOM method.

\section{Experimental section}

\section{Zeolite synthesis}

The reagents used included the chloride or hydroxide of $\mathrm{Li}^{+}$, $\mathrm{Na}^{+}, \mathrm{K}^{+}$and $\mathrm{Rb}^{+}$, as well as of $\mathrm{Ch}^{+}$, strontium nitrate $\left(\mathrm{Sr}\left(\mathrm{NO}_{3}\right)_{2}\right.$, $99 \%$, Aldrich), aluminum hydroxide $\left(\mathrm{Al}(\mathrm{OH})_{3} \cdot 1.0 \mathrm{H}_{2} \mathrm{O}\right.$, Aldrich) and colloidal silica (Ludox AS-40, Aldrich). In the case of the synthesis of Y, UZM-4, UZM-22, offretite and ferrierite, $\mathrm{Ch}^{+}$containing aluminosilicate gels were heated overnight at $95{ }^{\circ} \mathrm{C}$ prior to adding alkali or alkali earth metal cations. After being stirred at room temperature for 1 day, the final synthesis mixture was charged into Teflon-lined $23 \mathrm{~mL}$ autoclaves and heated under rotation $(60 \mathrm{rpm})$ at $100-150{ }^{\circ} \mathrm{C}$ for 7 or 14 days. The synthesis conditions for zeolites studied here are summarized in Table S1, ESI. $\dagger$ Levyne was synthesized via the so-called interzeolite conversion method under static conditions, where $\mathrm{H}-\mathrm{Y}$ with $\mathrm{Si} / \mathrm{Al}=15$ (Zeolyst) was used as both $\mathrm{Al}$ and Si sources. ${ }^{12}$

The solid products were recovered by filtration or centrifugation, washed repeatedly with distilled water and dried overnight at room temperature. To check whether the $\mathrm{Ch}^{+}$ions occluded in each zeolite product could be ion-exchanged, asmade zeolites were exchanged up to seven times in $2.0 \mathrm{M}$ $\mathrm{KNO}_{3}$ solutions ( $1 \mathrm{~g}$ solid per $100 \mathrm{~mL}$ solution) at $80^{\circ} \mathrm{C}$ for $8 \mathrm{~h}$. Also, Na-Y with $\mathrm{Si} / \mathrm{Al}=2.6$ (Tosoh) was exchanged four times in $1.0 \mathrm{M} \mathrm{ChCl}$ solutions ( $1 \mathrm{~g}$ solid per $100 \mathrm{~mL}$ solution) at $80^{\circ} \mathrm{C}$ for $8 \mathrm{~h}$. Here we refer to the repeatedly $\mathrm{K}^{+}$ion-exchanged as-made $\mathrm{Y}$ and $\mathrm{Ch}^{+}$ion-exchanged $\mathrm{Na}-\mathrm{Y}$ as $\mathrm{K}-\mathrm{Y}$ and $\mathrm{Ch}-\mathrm{Y}$, respectively.

\section{Analytical methods}

Powder X-ray diffraction (XRD) patterns were recorded on a PANalytical X'Pert diffractometer ( $\mathrm{Cu} \mathrm{K} \alpha$ radiation) with an $\mathrm{X}$ 'Celerator detector. Elemental analysis was performed on a Jarrell-Ash Polyscan 61E inductively coupled plasma spectrometer in combination with a Perkin-Elmer 5000 atomic absorption spectrophotometer. The $\mathrm{C}, \mathrm{H}$ and $\mathrm{N}$ contents of the samples were determined using a Vario EL III elemental organic analyzer. Thermogravimetric analyses (TGA) were carried out on an SII EXSTAR 6000 thermal analyzer, where the weight losses related to the combustion of OSDAs were further confirmed by differential thermal analyses (DTA) using the same analyzer. The crystal morphology and average size were determined using a JEOL JSM-6510 scanning electron microscope (SEM).

The ${ }^{1} \mathrm{H}^{13} \mathrm{C}$ CP MAS NMR spectra were recorded on a Varian Inova 300 spectrometer at a spinning rate of $6.0 \mathrm{kHz}$ and ${ }^{13} \mathrm{C}$ frequency of $75.428 \mathrm{MHz}$ with a $\pi / 2 \mathrm{rad}$ pulse length of $7.0 \mu \mathrm{s}$, a contact time of $2.5 \mathrm{~ms}$, a recycle delay of $3.0 \mathrm{~s}$ and an acquisition of $c a .5000$ pulse transients. The ${ }^{1} \mathrm{H}$ MAS NMR spectra were recorded on the same spectrometer at a ${ }^{1} \mathrm{H}$ frequency of 299.945 MHz with a $\pi / 2$ rad pulse length of $3.0 \mu \mathrm{s}$, a recycle delay of $2.0 \mathrm{~s}$ and an acquisition of $c a .100$ pulse transients. The ${ }^{13} \mathrm{C}$ and ${ }^{1} \mathrm{H}$ chemical shifts are reported relative to TMS.

The variable-temperature IR spectra in the $\mathrm{CH}$ and $\mathrm{OH}$ stretching regions of the occluded $\mathrm{Ch}^{+}$ions were measured on a Nicolet 6700 FT-IR spectrometer using self-supporting zeolite wafers of approximately $13 \mathrm{mg}$ (1.3 cm diameter). Prior to IR experiments, the zeolite wafers were dehydrated under vacuum $\left(10^{-4} \mathrm{~Pa}\right)$ at 180 or $200{ }^{\circ} \mathrm{C}$ for $6 \mathrm{~h}$ inside a home-built IR cell with $\mathrm{CaF}_{2}$ windows. Then, the IR spectra were recorded under vacuum from room temperature to $450{ }^{\circ} \mathrm{C}$ at a temperature interval of $50{ }^{\circ} \mathrm{C}$. Typically, 256 scans were accumulated. The Raman spectra were measured at room temperature on a Bruker FRA106/S FT-Raman spectrometer equipped with a Nd:YAG laser operating at $1064 \mathrm{~nm}$. A $5 \mathrm{~mm}$ NMR tube was used as the sample holder for both the solid powder and aqueous $\mathrm{ChCl}$ solution. The sample was exposed to a laser power of 100$250 \mathrm{~mW}$ at a spectral resolution of $2 \mathrm{~cm}^{-1}$. Typically, ca. 2000 scans were accumulated. Gaussian curve-fitting of the Raman spectra obtained was performed using the PeakFit curve-fitting program to determine the percentage ratio between the gauche 
and trans $\mathrm{Ch}^{+}$conformers in each sample by comparing the intensity of the Raman band at $710-715 \mathrm{~cm}^{-1}$ with that of the bands at $750-780 \mathrm{~cm}^{-1}$ (Fig. S1, ESI $\dagger$ ).

\section{Computational methods}

The 48T and 96T cluster models were extracted from the crystallographic data on zeolite $\mathrm{Y}$, which are available from the Structure Commission of the International Zeolite Association (IZA-SC), ${ }^{20}$ and employed to calculate the relative energies of gauche, trans and trans $\mathrm{Ch}^{+}$conformers embedded in the 14-hedral $\left(\left[4^{6} 6^{8}\right]\right)$ sod cage and 26-hedral $\left(\left[4^{18} 6^{4} 12^{4}\right]\right)$ supercage, respectively. The same energy calculations were also performed on these three conformers in the $78 \mathrm{~T}$ ferrierite channel intersection, 76T ferrierite 16-hedral $\left(\left[5^{8} 6^{6} 8^{2}\right]\right)$ fer cage, 64T phillipsite, 88T EU-12 and 60T levyne models derived from the IZA-SC database. All zeolite models were treated as pure-silica frameworks so that the electrostatic (coulombic) interactions between the OSDA and the zeolite framework were not included in the calculations. OSDAs were fixed in their specified conformations and allowed to settle to their most energetically favorable positions. The terminal $\mathrm{Si}$ atoms at all cluster edges were capped with $\mathrm{H}$ atoms at a $\mathrm{Si}-\mathrm{H}$ bond distance of $1.47 \AA$ oriented along the direction of the corresponding $\mathrm{Si}-\mathrm{O}$ bond.

The ONIOM ( $\omega \mathrm{B} 97 \mathrm{XD} / 6-31 \mathrm{G}(\mathrm{d}, \mathrm{p})$ :MNDO) method was applied to optimize the geometries of OSDA molecules within various zeolite structures using the Gaussian 09 program package. ${ }^{21}$ During the geometric optimization, the $24,48,20,20$, 24, 24 and 30 tetrahedral atoms (T-atoms) surrounding each $\mathrm{Ch}^{+}$conformer within the Y sod cage, Y supercage, ferrierite channel intersection, ferrierite fer cage, phillipsite, EU-12 and levyne, respectively, as well as $\mathrm{Ch}^{+}$conformer itself, were treated at the high $\omega$ B97XD level. The rest of the T-atoms in each theoretical model were treated at the low MNDO level, while being kept fixed at their crystallographic locations. To maintain the specific conformation (i.e., the gauche, trans, or trans ${ }^{\prime}$ form) of $\mathrm{Ch}^{+}$, the $\mathrm{N}-\mathrm{C}-\mathrm{C}-\mathrm{O}$ and $\mathrm{C}-\mathrm{C}-\mathrm{O}-\mathrm{H}$ dihedral angles were constrained to 60 and $180^{\circ}, 180$ and $180^{\circ}$ and 180 and $90^{\circ}$, respectively. The single-point energy calculations were further refined at the $\omega \mathrm{B} 97 \mathrm{XD} / 6-31 \mathrm{G}(\mathrm{d}, \mathrm{p})$ level using the optimized structures.

For a given $\mathrm{Ch}^{+}$conformer in a given ZEO framework, the relative energy to its gauche conformer is defined as

$$
E_{\mathrm{rel}}=E_{\mathrm{OSDA} / \mathrm{ZEO}}-E_{\text {gauche/ZEO }}
$$

where $E_{\text {OSDA/ZEO }}$ is the energy of the optimized cluster model consisting of the zeolite framework and one of the three $\mathrm{Ch}^{+}$ conformers. The total stabilization energies of the three representative $\mathrm{Ch}^{+}$conformers in zeolite frameworks are derived from a combination of two contributions: one due to the deformation of the zeolite framework and each of the three different $\mathrm{Ch}^{+}$conformers and the other due to the intermolecular interactions of each $\mathrm{Ch}^{+}$conformer with the zeolite framework. The total deformation and stabilization energies are therefore

$$
E_{\mathrm{def}}=\Delta E_{\mathrm{def}(\mathrm{ZEO})}+\Delta E_{\mathrm{def}(\mathrm{OSDA})}
$$

$$
\Delta E_{\mathrm{tot}}=E_{\mathrm{def}}+\Delta E_{\mathrm{int}}
$$

where $\Delta E_{\operatorname{def}(\mathrm{ZEO})}$ and $\Delta E_{\operatorname{def}(\mathrm{OSDA})}$ are the deformation energies of the zeolite framework and each $\mathrm{Ch}^{+}$conformer, respectively, and $\Delta E_{\text {int }}$ is the interaction energy between them. $\Delta E_{\text {int }}$, $\Delta E_{\text {def(ZEO) }}$ and $\Delta E_{\text {def(OSDA) }}$ are

$$
\begin{gathered}
\Delta E_{\mathrm{int}}=E_{\mathrm{OSDA} / \mathrm{ZEO}}-E_{(\mathrm{ZEO})}^{\mathrm{c}}-E_{(\mathrm{OSDA})}^{\mathrm{c}} \\
\Delta E_{\mathrm{def}(\mathrm{ZEO})}=E_{(\mathrm{ZEO})}^{\mathrm{c}}-E_{(\mathrm{ZEO})} \\
\Delta E_{\mathrm{def}(\mathrm{OSDA})}=E_{(\mathrm{OSDA})}^{\mathrm{c}}-E_{(\mathrm{OSDA})}
\end{gathered}
$$

where $E_{(\mathrm{ZEO})}^{\mathrm{c}}$ and $E_{(\mathrm{OSDA})}^{\mathrm{c}}$ are the energies of the zeolite framework and each $\mathrm{Ch}^{+}$conformer, respectively, extracted from the optimized cluster model without further optimization. Also, $E_{(\mathrm{ZEO})}$ and $E_{(\mathrm{OSDA})}$ are the energies of the zeolite framework and each $\mathrm{Ch}^{+}$conformer at its gas-phase equilibrium geometry, respectively.

\section{Results and discussion}

Comparison of the powder XRD patterns of the eight zeolites with different framework topologies synthesized using $\mathrm{Ch}^{+}$as an OSDA with those in the literature ${ }^{20}$ shows that all of them are phase pure (Fig. S2, ESI $\dagger$ ). As previously reported,,$^{10}$ however, the XRD pattern of ferrierite was fairly broader than that of the typical corresponding zeolite, mainly due to its nanocrystallinity, which may also be the case for offretite (Fig. S3, ESI $\dagger$ ). The chemical composition data in Table 1 indicate that the $\mathrm{C} / \mathrm{N}$ ratio of occluded organic species is always close to that (5) of $\mathrm{Ch}^{+}$ions. This suggests that most of them remain intact upon encapsulation into the pores of zeolites synthesized here. From TGA/DTA experiments, no noticeable decrease in organic content was observed for small-pore (phillipsite, EU-12 and levyne) and medium-pore (ferrierite) zeolites, even after repeated $\mathrm{K}^{+}$ion exchange. As shown in Fig. S4 (ESI $\dagger$ ), however, there is a significant decrease in organic content for all largepore zeolites (Y, UZM-4, UZM-22 and offretite). It thus appears that the kinetic diameter of $\mathrm{Ch}^{+}$ions may be between $5.4 \AA$, the longest dimension of elliptical 10-ring channels in ferrierite and 6.3 $\AA$, the diameter of 12-ring channels in UZM-4, which is the smallest among the four large-pore zeolites studied. ${ }^{20}$

Fig. 2 shows the Raman spectra in the $600-3100 \mathrm{~cm}^{-1}$ region of Y, K-Y, Ch-Y, UZM-4, UZM-22, offretite, ferrierite, phillipsite, EU-12 and levyne, all of which contain $\mathrm{Ch}^{+}$as a guest molecule. Akutsu was the first to recognize that the symmetric stretching vibration of four $\mathrm{C}-\mathrm{N}$ bonds in $\mathrm{Ch}^{+}$could be related to the $\mathrm{N}-\mathrm{C}-$ $\mathrm{C}-\mathrm{O}$ dihedral angle in this organic cation from the comparison of the Raman spectra of a series of $\mathrm{Ch}^{+}$ions selectively deuterated at different positions. ${ }^{22} \mathrm{He}$ was able to assign two Raman band appearing around 720 and $770 \mathrm{~cm}^{-1}$ to the symmetric $\mathrm{C}-\mathrm{N}$ stretching mode $\left(\nu_{\mathrm{s}}(\mathrm{C}-\mathrm{N})\right)$ of gauche and trans $\mathrm{Ch}^{+}$conformers, respectively, based on the crystallographically determined conformations of various $\mathrm{Ch}^{+}$-containing salts. The spectrum of ChCl in aqueous solution, which exhibits a weak band at $765 \mathrm{~cm}^{-1}$ due to the $\nu_{\mathrm{s}}(\mathrm{C}-\mathrm{N})$ mode of trans $\mathrm{Ch}^{+}$, together with 
Table 1 Characterization data for as-made zeolites synthesized in this work

\begin{tabular}{|c|c|c|c|c|c|c|c|c|c|}
\hline Zeolite & $\% \mathrm{~N}$ & $\% \mathrm{C}$ & $\% \mathrm{H}$ & $\% \sum^{a}$ & $\mathrm{C} / \mathrm{N}$ & Unit cell composition $^{b}$ & $\mathrm{Si} / \mathrm{Al}$ & $\begin{array}{l}\text { Crystal shape } \\
\text { and } \operatorname{size}^{c}(\mu \mathrm{m})\end{array}$ & $\begin{array}{l}\% \text { gauche } \\
\mathrm{Ch}^{+d}\end{array}$ \\
\hline ChCl salt & & & & & & & & & 100 \\
\hline $\mathrm{Y}$ & 2.22 & 9.54 & 3.40 & $15.16(17.3)$ & 4.97 & $\left|\mathrm{Ch}_{25.4} \mathrm{Na}_{34.8} \mathrm{H}_{4.5}\left(\mathrm{H}_{2} \mathrm{O}\right)_{117.6}\right|\left[\mathrm{Al}_{64.7} \mathrm{Si}_{127.3} \mathrm{O}_{384}\right]$ & 2.0 & Polyhedrons, $1.0 \times 1.5$ & 81 \\
\hline $\mathrm{K}-\mathrm{Y}$ & 0.22 & 0.96 & 0.18 & $1.36(1.77)$ & 5.09 & $\left|\mathrm{Ch}_{3.0} \mathrm{Na}_{2.2} \mathrm{~K}_{56.7} \mathrm{H}_{2.7}\left(\mathrm{H}_{2} \mathrm{O}\right)_{204.0}\right|\left[\mathrm{Al}_{64.7} \mathrm{Si}_{127.3} \mathrm{O}_{384}\right]$ & 2.0 & Polyhedrons, $1.0 \times 1.5$ & 0 \\
\hline $\mathrm{Ch}-\mathrm{Y}$ & 1.46 & 6.35 & 2.25 & $10.06(13.3)$ & 5.07 & $\left|\mathrm{Ch}_{21.1} \mathrm{Na}_{34.3} \mathrm{OH}_{0.66}\left(\mathrm{H}_{2} \mathrm{O}\right)_{116.5}\right|\left[\mathrm{Al}_{54.8} \mathrm{Si}_{137.2} \mathrm{O}_{384}\right]$ & 2.6 & Polyhedrons, $0.7 \times 1.0$ & 100 \\
\hline Offretite & 2.43 & 10.52 & 3.39 & $16.34(17.8)$ & 5.01 & $\left|\mathrm{Ch}_{2.0} \mathrm{~K}_{0.6} \mathrm{Sr}_{0.5} \mathrm{OH}_{0.3}\left(\mathrm{H}_{2} \mathrm{O}\right)_{5.0}\right|\left[\mathrm{Al}_{3.8} \mathrm{Si}_{14.1} \mathrm{O}_{36}\right]$ & 3.7 & Spheres, 0.05 & 92 \\
\hline Ferrierite & 2.30 & 9.83 & 2.48 & $14.61(16.2)$ & 4.94 & $\left|\mathrm{Ch}_{3.0} \mathrm{Na}_{0.6} \mathrm{OH}_{0.3}\left(\mathrm{H}_{2} \mathrm{O}\right)_{5.3}\right|\left[\mathrm{Al}_{3.3} \mathrm{Si}_{32.7} \mathrm{O}_{72}\right]$ & 9.9 & Needles, $0.01 \times 0.1$ & 13 \\
\hline Phillipsite & 1.09 & 3.97 & 1.83 & $6.89(6.64)$ & 4.24 & $\left|\mathrm{Ch}_{1.7} \mathrm{Na}_{0.1} \mathrm{Rb}_{4.0} \mathrm{OH}_{0.2}\left(\mathrm{H}_{2} \mathrm{O}\right)_{11.4}\right|\left[\mathrm{Al}_{5.5} \mathrm{Si}_{26.5} \mathrm{O}_{64}\right]$ & 4.8 & Rhombohedrons, 3.0 & 0 \\
\hline EU-12 & 1.08 & 4.48 & 1.51 & $7.08(7.67)$ & 4.82 & $\left|\mathrm{Ch}_{3.9} \mathrm{Na}_{0.2} \mathrm{Rb}_{4.7} \mathrm{OH}_{1.6}\left(\mathrm{H}_{2} \mathrm{O}\right)_{8.4}\right|\left[\mathrm{Al}_{7.2} \mathrm{Si}_{64.8} \mathrm{O}_{144}\right]$ & 9.0 & Needles, $0.1 \times 1.0$ & 0 \\
\hline Levyne & 2.23 & 9.62 & 2.89 & $14.74(17.3)$ & 4.99 & $\left|\mathrm{Ch}_{6.1} \mathrm{Na}_{1.9} \mathrm{OH}_{2.3}\left(\mathrm{H}_{2} \mathrm{O}\right)_{12.5}\right|\left[\mathrm{Al}_{5.7} \mathrm{Si}_{48.3} \mathrm{O}_{108}\right]$ & 8.5 & Circular platelets, & 100 \\
\hline
\end{tabular}

${ }^{a}$ The total organic contents in wt $\%$. The values given in parentheses are the exothermic weight losses by TGA/DTA at $200-800{ }^{\circ} \mathrm{C}$ for $\mathrm{Y}$ and at $250-$ $800{ }^{\circ} \mathrm{C}$ for the other zeolites. ${ }^{b} \mathrm{H}^{+}$or $\mathrm{OH}^{-}$has been introduced to make the as-made zeolites electrically neutral. The water content was calculated from the endothermic weight loss by TGA/DTA up to $200^{\circ} \mathrm{C}$ for Y and to $250{ }^{\circ} \mathrm{C}$ for the other zeolites (Fig. S7, ESI). ${ }^{c}$ Determined by SEM. ${ }^{d}$ The percentage of the gauche conformer of $\mathrm{Ch}^{+}$ions in each zeolite was determined by dividing the area of its Raman band appearing at 713$715 \mathrm{~cm}^{-1}$ by the areas of the Raman band at $750-772 \mathrm{~cm}^{-1}$ due to the trans conformer and of the band at $713-715 \mathrm{~cm}^{-1}$ (Fig. 2).

a much stronger band at $715 \mathrm{~cm}^{-1}$ assigned to the same vibration mode of gauche $\mathrm{Ch}^{+},{ }^{22,23}$ is also compared in Fig. 2. It can be seen that the relative intensities of the $\mathrm{C}-\mathrm{H}$ stretching bands at 2800-3100 $\mathrm{cm}^{-1}$ and the $\mathrm{CH}_{2}$ bending band around $1450 \mathrm{~cm}^{-1}$, as well as the $\nu_{\mathrm{s}}(\mathrm{C}-\mathrm{N})$ and $\nu_{\text {as }}(\mathrm{C}-\mathrm{N})$ bands at $850-$ $960 \mathrm{~cm}^{-1}$, in the spectra of these eight zeolites are generally similar to one another, whereas the opposite holds for the $\nu_{\mathrm{s}}(\mathrm{C}-\mathrm{N})$ bands appearing at 713-715 $\mathrm{cm}^{-1}$ and $750-772 \mathrm{~cm}^{-1}$. This indicates that the $\mathrm{Ch}^{+}$ions exist intact within the void

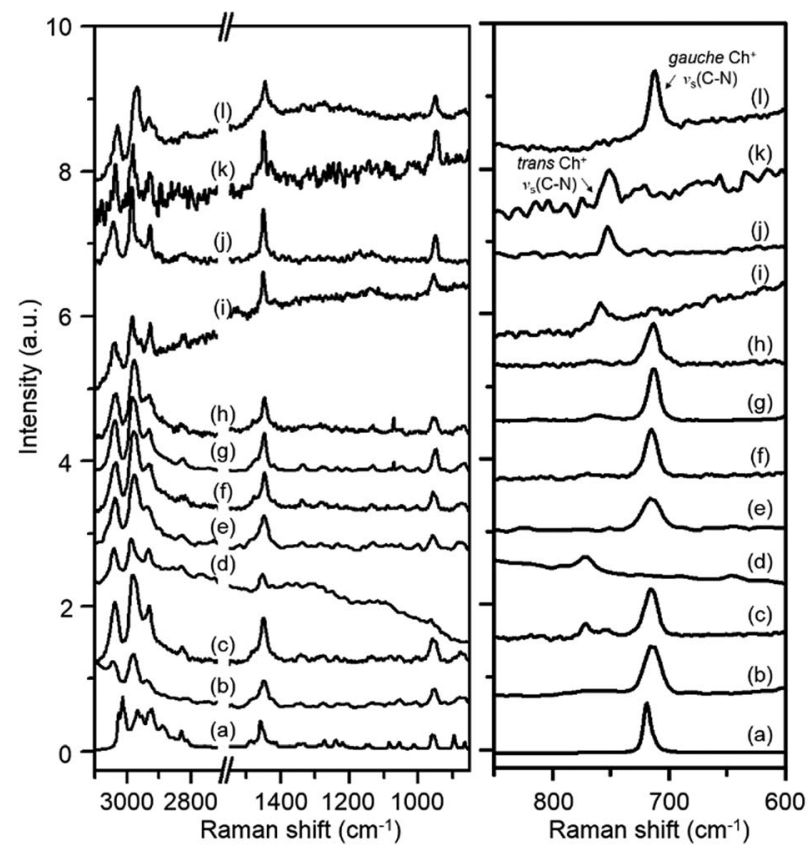

Fig. 2 Raman spectra of $\mathrm{ChCl}$ in (a) solid and (b) $0.5 \mathrm{M}$ aqueous solution states, and as-made (c) $Y$, (d) $K-Y$, (e) $C h-Y$, (f) UZM-4, (g) UZM-22, (h) offretite, (i) ferrierite, (j) phillipsite, (k) EU-12 and (l) levyne prepared using $\mathrm{Ch}^{+}$as an OSDA. space of each material, but the intrazeolitic distribution of gauche and trans conformers varies notably with the zeolite pore structure.

Table 1 lists the gauche conformer percentages of $\mathrm{Ch}^{+}$ions in the series of as-made zeolites with different framework structures determined by comparing the integrated intensities of their $\nu_{\mathrm{s}}(\mathrm{C}-\mathrm{N})$ bands. Like the case of $\mathrm{ChCl}$ in aqueous solution, the majority, but not all, of OSDAs in Y, UZM-4, UZM-22 and offretite were found to have a gauche conformation. It is worth noting that the Raman spectrum of Y gives two weak bands at 754 and $772 \mathrm{~cm}^{-1}$, as well as one stronger band at $715 \mathrm{~cm}^{-1}$, showing the existence of two environments for trans $\mathrm{Ch}^{+}$. An unexpected finding is that the Raman spectrum of levyne shows the most prominent Raman band at $713 \mathrm{~cm}^{-1}$ from gauche $\mathrm{Ch}^{+}$, with no detectable bands in the region higher than $750 \mathrm{~cm}^{-1}$ (Fig. 2), although its 17-hedral $\left(\left[4^{9} 6^{5} 8^{3}\right]\right)$ lev cage is considerably smaller than the 26-hedral $\left(\left[4^{18} 6^{4} 12^{4}\right]\right)$ supercage in Y. From elemental analysis, each lev cage in as-made levyne was calculated to contain one $\mathrm{Ch}^{+}$ion on average (Table 1). Clearly, the crystallographic dimensions $(8.0 \times 8.0 \times 7.0 \AA)$ of this cage $\mathrm{e}^{20}$ would be large enough to accommodate one $\mathrm{Ch}^{+}$ion with little hindrance, but not two cations. Given its 8-ring window size $(3.6 \times 4.8 \AA)$, therefore, it is not difficult to conclude that the $\mathrm{Ch}^{+}$ions in levyne are entirely isolated from one another and thus exist as the more stable gauche conformer.

The most interesting observation from Table 1 and Fig. 2 is that when as-made $\mathrm{Y}$ was repeatedly exchanged in $2.0 \mathrm{M} \mathrm{KNO}_{3}$ solutions, the resulting solid (i.e., $\mathrm{K}-\mathrm{Y}$ ) shows only one small $\nu_{\mathrm{s}}(\mathrm{C}-\mathrm{N})$ band at $772 \mathrm{~cm}^{-1}$ : the two bands at 715 and $754 \mathrm{~cm}^{-1}$ are not observed anymore. This clearly shows that the remaining $\mathrm{Ch}^{+}$ions in $\mathrm{K}-\mathrm{Y}$ are located within non-exchangeable sites (i.e., 14-hedral ([ $\left.\left.4^{6} 6^{8}\right]\right)$ sod cages) and are present only as a trans conformer. From comparison with the Raman spectrum of the parent $\mathrm{Y}$ zeolite, we were also aware that a non-negligible part $(11 \%)$ of OSDA molecules within the large supercages in as- 
made $\mathrm{Y}$, which can be easily removed by $\mathrm{K}^{+}$ion exchange, exists as a trans conformer. However, the Raman spectrum of $\mathrm{Ch}-\mathrm{Y}$, where an average of $c a .2 .6 \mathrm{Ch}^{+}$ions were exchanged into its supercages (according to TGA/DTA analysis), with no organic cations within the sod cages, exhibits only one strong $\nu_{\mathrm{s}}(\mathrm{C}-\mathrm{N})$ band at $715 \mathrm{~cm}^{-1}$, indicating the absence of any trans $\mathrm{Ch}^{+}$. Therefore, the guest-guest interactions within the supercages in the parent $\mathrm{Y}$ appear to be considerably different from those in $\mathrm{Ch}-\mathrm{Y}$. It is interesting to note here that the $\nu_{\mathrm{s}}(\mathrm{C}-\mathrm{N})$ band position $\left(754 \mathrm{~cm}^{-1}\right)$ of trans $\mathrm{Ch}^{+}$within the supercages is lower by $c a$. $20 \mathrm{~cm}^{-1}$ than that $\left(772 \mathrm{~cm}^{-1}\right)$ of trans $\mathrm{Ch}^{+}$within the much smaller sod cages. This led us to conclude that the $\nu_{\mathrm{s}}(\mathrm{C}-\mathrm{N})$ band position of $\mathrm{Ch}^{+}$is highly sensitive to the size of the zeolite cage within which the cation is located, as well as to the type of its molecular conformation.

One may speculate that $\mathrm{Ch}^{+}$is too large to be accommodated within the sod cages of zeolite $\mathrm{Y}$ without causing severe geometric constraints. If this is the case, then the reason $\mathrm{K}-\mathrm{Y}$ shows a $\nu_{\mathrm{S}}(\mathrm{C}-\mathrm{N})$ band at $772 \mathrm{~cm}^{-1}$ would be a result of the presence of $\mathrm{TMA}^{+}$within the sod cages that could be produced by $\mathrm{Ch}^{+}$decomposition during the synthesis of this cage-based large-pore zeolite. In fact, the Raman spectrum of $\mathrm{Y}$ crystallized using $\mathrm{TMA}^{+}$as an OSDA is reported to exhibit a $\nu_{\mathrm{s}}(\mathrm{C}-\mathrm{N})$ band at essentially the same position $\left(773 \mathrm{~cm}^{-1}\right) \cdot{ }^{24}$ However, since the crystallization temperature $\left(115^{\circ} \mathrm{C}\right)$ of our $\mathrm{Y}$ is lower than the decomposition temperature $\left(c a .135{ }^{\circ} \mathrm{C}\right)$ of $\mathrm{Ch}^{+},{ }^{12}$ it is most likely that the occluded species within its sod cages is not $\mathrm{TMA}^{+}$but $\mathrm{Ch}^{+}$. Further evidence for this will be given below. On the other hand, the majority (87\%) of organic cations in ferrierite are characterized by a trans conformation. As shown in Fig. 2, however, there is only one $\nu_{\mathrm{s}}(\mathrm{C}-\mathrm{N})$ band around $750 \mathrm{~cm}^{-1}$ in the Raman spectra of phillipsite and EU-12, implying the sole presence of trans $\mathrm{Ch}^{+}$ions. This can be rationalized by considering the narrow feature of their 8-ring channels, in contrast to our recent study on the structure of as-made EU-12: ${ }^{11}$ it is still not easy to accurately determine the conformation of flexible OSDAs like $\mathrm{Ch}^{+}$in zeolites using the Rietveld refinement of powder XRD data.

The ${ }^{1} \mathrm{H}^{-13} \mathrm{C}$ CP MAS NMR spectra of the eight zeolites synthesized using $\mathrm{Ch}^{+}$and $\mathrm{K}-\mathrm{Y}$, together with the liquid ${ }^{13} \mathrm{C}$ NMR spectrum in $\mathrm{D}_{2} \mathrm{O}$ solution of $\mathrm{ChCl}$, can be found in Fig. $\mathrm{S} 5$ $(\mathrm{ESI} \dagger)$. Differences in the number and relative intensity of the observed ${ }^{13} \mathrm{C}$ resonances reveal that $\mathrm{Ch}^{+}$experiences a chemical environment that is different in each zeolite. It is also remarkable that the resonance of the methylene carbon bonded to the nitrogen in this asymmetric guest species appearing at 67$69 \mathrm{ppm}$ is very weak or hardly detectable in the spectra of $\mathrm{K}-\mathrm{Y}$, phillipsite and EU-12. Recall that all $\mathrm{Ch}^{+}$ions occluded in these three zeolites adopt a trans conformation as evidenced by Raman results (Fig. 2). However, the methylene carbon resonance was found to be clearly visible in the ${ }^{1} \mathrm{H}^{-13} \mathrm{C}$ CP MAS NMR spectra of zeolites with high percentages of gauche $\mathrm{Ch}^{+}$and, particularly, of levyne where the OSDA molecules are all in the gauche conformation (Table 1). Therefore, one may speculate that the methylene carbon in trans $\mathrm{Ch}^{+}$is less mobile than that in gauche $\mathrm{Ch}^{+}$, because the intrazeolitic environments of the former conformer, such as sod cages and EU-12 8-ring channels, are spatially highly restricted. However, this situation should also be the case of the other two types of carbon atoms (i.e., the methyl carbons and the methylene carbon bonded to the oxygen) in $\mathrm{Ch}^{+}$. If so, the protons of the methylene carbon bonded to the nitrogen appear to have a lower ${ }^{1} \mathrm{H}^{-13} \mathrm{C}$ crosspolarization efficiency.

Fig. 3 shows the variable-temperature IR spectra in the $\mathrm{CH}$ and $\mathrm{OH}$ stretching regions of zeolites studied in this work. Comparison of their room temperature spectra with the spectrum of $\mathrm{ChCl}$ again confirms that the $\mathrm{Ch}^{+}$ions remain intact upon occlusion in the pores of each zeolite, which is also the case of the cations in $\mathrm{K}-\mathrm{Y}$. We also note that the position of the $\mathrm{OH}$ stretching vibration band(s) from intrazeolitic $\mathrm{Ch}^{+}$ions is always blue-shifted compared with that $\left(c a .3260 \mathrm{~cm}^{-1}\right)$ of the $\mathrm{OH}$ stretching band from ChCl. Thus, although all zeolite synthesis mixtures employed here included some amount of $\mathrm{Cl}^{-}$anions (Table S1, ESI $\dagger$ ), we can exclude the possibility of intermolecular hydrogen bonding between the $\mathrm{Ch}^{+} \mathrm{OH}$ group and the $\mathrm{Cl}^{-}$ion $\left(\mathrm{O}-\mathrm{H} \cdots \mathrm{Cl}^{-}\right)$in any of our zeolites. We can also ignore the contribution of hydrogen-bonded $\mathrm{SiOH}$ groups, if present, to the $\mathrm{OH}$ stretching vibration band(s) appearing around $3300-3600 \mathrm{~cm}^{-1}$. This is because none of the ${ }^{1} \mathrm{H}$ MAS NMR spectra of zeolites studied here gave any noticeable resonances due to the hydrogen-bonded $\mathrm{SiOH}$ groups ${ }^{25,26}$ in the chemical shift region above 10 ppm (Fig. S6, ESI $\dagger$ ).

An interesting observation from Fig. 3 is that the extent of the blue shift in the $\mathrm{OH}$ stretching band differs markedly according to not only the structure type of zeolites containing $\mathrm{Ch}^{+}$ions, but also the intrazeolitic location of this $\mathrm{OH}$ groupcontaining guest species. For example, the room-temperature IR spectrum of $\mathrm{K}-\mathrm{Y}$ exhibits a broad $\mathrm{OH}$ stretching band around $3590 \mathrm{~cm}^{-1}$ which is much higher than the position (ca. $3280 \mathrm{~cm}^{-1}$ ) of the $\mathrm{OH}$ stretching band in the spectrum of Y. Because its $\mathrm{Ch}^{+}$ions are all located as a trans conformer within the sod cages (Fig. 2), the $\mathrm{OH}$ group cannot form intramolecular hydrogen bonding and should thus be in a state similar to that in the free $\mathrm{Ch}^{+}$ion. In fact, the $\mathrm{OH}$ stretching band of alcohols, such as ethanol and propanol, in the gas phase or in non-polar solvents typically occurs in the 3580$3670 \mathrm{~cm}^{-1}$ region. ${ }^{27}$

Fig. 3 also shows that the room-temperature IR spectra of OSDA molecules in the other three large-pore but channelbased zeolites UZM-4, UZM-22 and offretite, most of which have a gauche conformation, present an $\mathrm{OH}$ stretching band around 3370,3370 and $3410 \mathrm{~cm}^{-1}$, respectively. While these band positions are still lower than the position $\left(c a .3590 \mathrm{~cm}^{-1}\right)$ of the $\mathrm{OH}$ stretching band found in the spectrum of $\mathrm{K}-\mathrm{Y}$, they are rather higher than that $\left(3280 \mathrm{~cm}^{-1}\right)$ of the corresponding band from Y. More interestingly, with increasing IR measurement temperature, all the $\mathrm{OH}$ stretching bands from UZM-4, UZM-22 and offretite are shifted to a higher wavenumber region. As shown in Fig. 3, however, the highest position of their $\mathrm{OH}$ stretching band ( $c a .3550 \mathrm{~cm}^{-1}$ ) was observed at $300{ }^{\circ} \mathrm{C}$. Clearly, if the $\mathrm{Ch}^{+}$ions in these large-pore zeolites have intramolecular hydrogen bonding between the protons of the $\mathrm{CH}_{3}$ group and the oxygen of the $\mathrm{OH}$ group $(\mathrm{C}-\mathrm{H} \cdots \mathrm{O}-\mathrm{H})$, their free form would then be generated at elevated temperatures, giving 

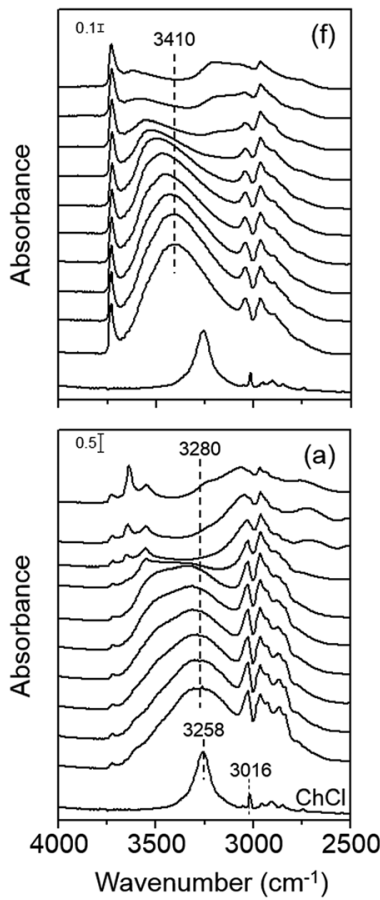
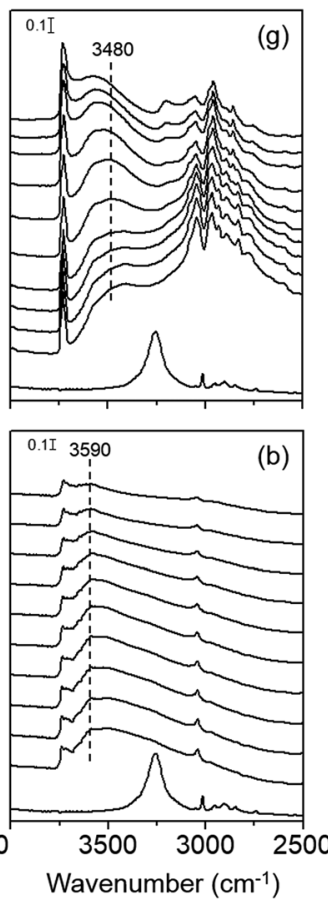
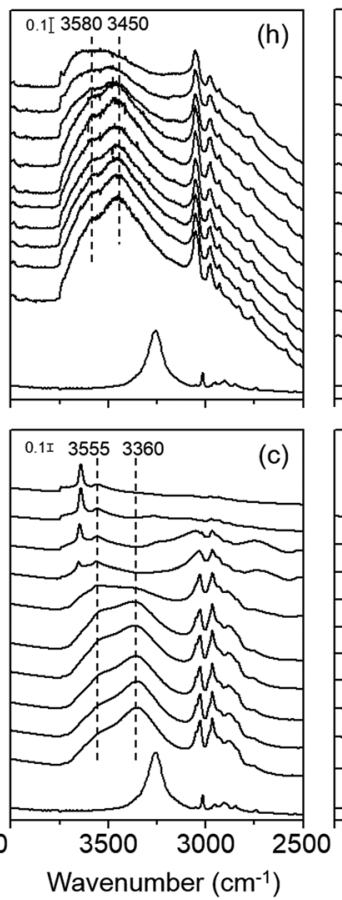
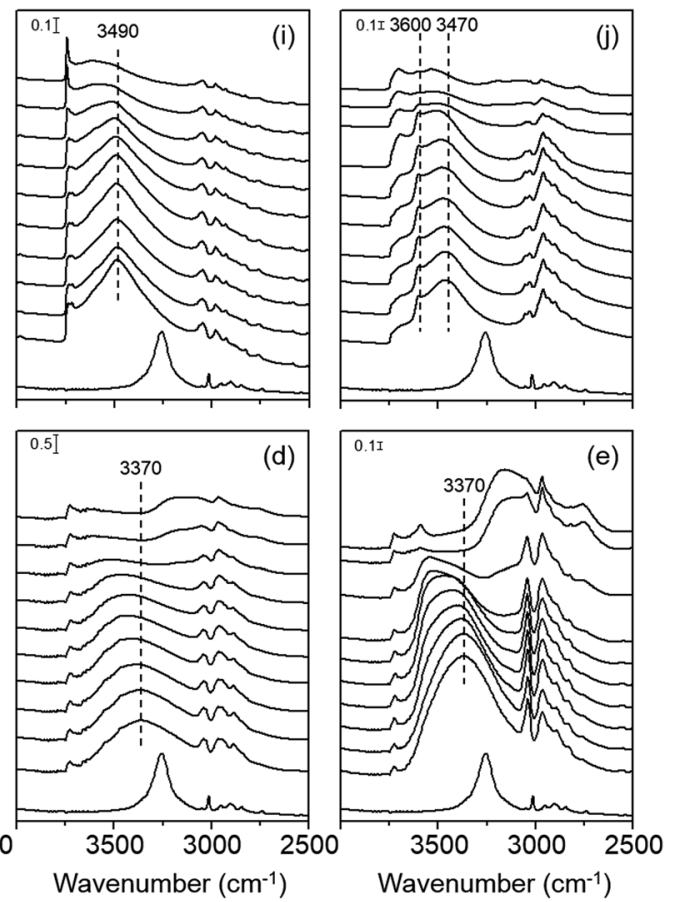

Fig. 3 IR spectra in the $2500-4000 \mathrm{~cm}^{-1}$ region of as-made (a) $Y$, (b) $K-Y$, (c) Ch-Y, (d) UZM-4, (e) UZM-22, (f) offretite, (g) ferrierite, (h) phillipsite, (i) EU-12 and (j) levyne recorded at temperatures ranging from room temperature (bottom) to $450{ }^{\circ} \mathrm{C}$ (top) at intervals of $50{ }^{\circ} \mathrm{C}$. The bottom trace in each panel is the spectrum of $\mathrm{ChCl}$ recorded at room temperature.

a fairly narrower $\mathrm{OH}$ stretching band at $3590 \mathrm{~cm}^{-1}$ or higher, due to the weak nature of intramolecular hydrogen bonding and the higher mobility of free $\mathrm{OH}$ groups. Therefore, no intramolecular hydrogen bonding appears to exist within the $\mathrm{Ch}^{+}$ ions in UZM-22, as well as in UZM-4 and offretite.
Another interesting but unexpected result from Fig. 3 is that the room-temperature IR spectrum in the $\mathrm{OH}$ region of as-made levyne shows two bands around 3470 and $3600 \mathrm{~cm}^{-1}$, although each of its $\mathrm{Ch}^{+}$cations is completely isolated as a gauche conformer within the lev cage (Table 1 and Fig. 2). We note here

(g)

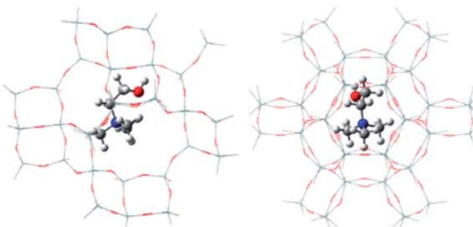

(d)

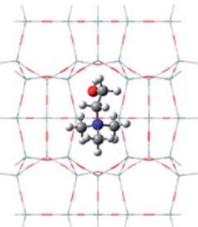

(a)

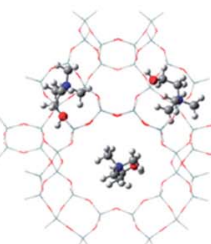

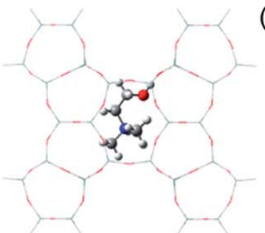

(e)

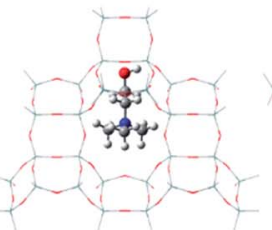

(b)

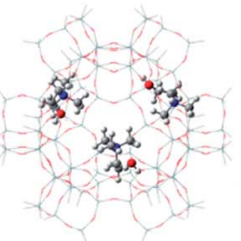

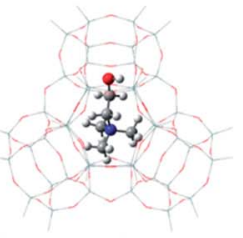
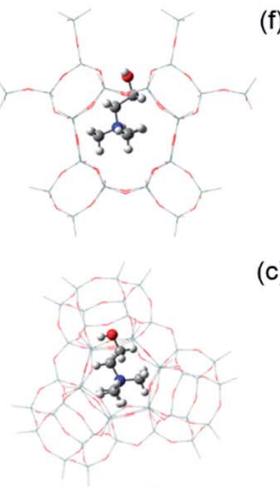

(f)

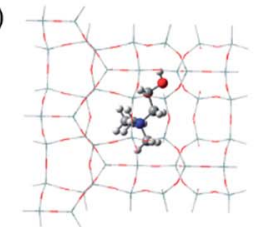

(c)

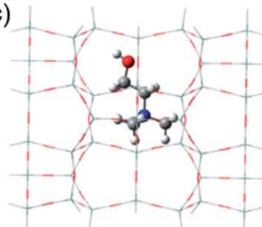

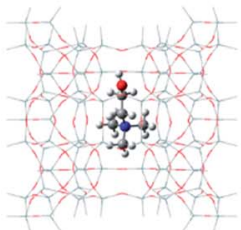

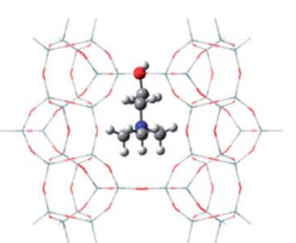

Fig. 4 Side (left) and top (right) views of the structures of the most stable $\mathrm{Ch}^{+}$conformer embedded in zeolites with different framework topologies: (a) gauche $\mathrm{Ch}^{+}$in the $\mathrm{Y}$ supercage, (b) trans $\mathrm{Ch}^{+}$in the $\mathrm{Y}$ sod cage, (c) trans $\mathrm{Ch}^{+}$in the ferrierite channel intersection, (d) gauche $\mathrm{Ch}^{+}$ in the ferrierite fer cage, (e) trans ${ }^{\prime} \mathrm{Ch}^{+}$in phillipsite, (f) trans $\mathrm{Ch}^{+}$in $\mathrm{EU}-12$ and (g) gauche $\mathrm{Ch}^{+}$in levyne. Notice that the $\mathrm{Y}$ supercage model contains three $\mathrm{Ch}^{+}$ions, whereas the other six cluster models have one $\mathrm{Ch}^{+}$ion. All the structures were optimized at the ONIOM ( $\omega \mathrm{B} 97 \mathrm{XD} / 6-$ $31 \mathrm{G}(\mathrm{d}, \mathrm{p}): \mathrm{MNDO}$ ) level of theory. To clearly display the conformation of $\mathrm{Ch}^{+}$, the T-atoms in each theoretical model treated at the high $\omega \mathrm{B97XD}$ level, as well as those treated at the low MNDO level, are represented as wire-frame models. Si, dark cyan; O, red; H, white; C, gray; N, blue. 
that the position ( $\left.c a .3600 \mathrm{~cm}^{-1}\right)$ of a narrower $\mathrm{OH}$ stretching band is marginally higher than that $\left(c a .3590 \mathrm{~cm}^{-1}\right)$ observed for $\mathrm{K}-\mathrm{Y}$. The fact that no noticeable changes in the position and width of this band are caused by an increase in IR measurement temperature up to $300{ }^{\circ} \mathrm{C}$ suggests its free nature. A similar temperature independence can be observed for the other broad band appearing around $3470 \mathrm{~cm}^{-1}$. Assuming that the $\mathrm{Al}$ atoms are randomly distributed in the framework, our levyne was calculated to possess approximately one $\mathrm{Al}$ atom per lev cage, matching the number of $\mathrm{Ch}^{+}$ions per cage. This allowed us to assign a broad band around $3470 \mathrm{~cm}^{-1}$ to the $\mathrm{OH}$ group of OSDAs involved in intermolecular electrostatic interactions with the negatively charged zeolite framework. Since as-made levyne also has $c a .0 .3 \mathrm{Na}^{+}$ions per cage (Table 1), however, about one of the three $\mathrm{Ch}^{+}$ions does not necessarily compensate for the framework negative charge created by Al substitution. Therefore, we assign the relatively narrower band around $3600 \mathrm{~cm}^{-1}$ to the $\mathrm{OH}$ group of $\mathrm{Ch}^{+}$ions not involved in electrostatic interactions. Fig. 3 also shows that unlike that of $Y$, the room-temperature IR spectrum of $\mathrm{Ch}-\mathrm{Y}$ is characterized by two $\mathrm{OH}$ stretching bands around 3360 and $3560 \mathrm{~cm}^{-1}$, where the intensity of the high-wavenumber band is quite weaker. Because a combination of elemental and thermal analyses on $\mathrm{Ch}-\mathrm{Y}$ indicates that the sum (55.4) of the numbers per unit cell of $\mathrm{Ch}^{+}$and $\mathrm{Na}^{+}$ions is almost the same as the number (54.8) per unit cell of framework $\mathrm{Al}$ atoms, the $\mathrm{Ch}^{+}$ions within the supercages in $\mathrm{Ch}-\mathrm{Y}$ may counterbalance the framework negative charge. Therefore, it is clear that the nature of guest-guest interactions within the supercages is different for $\mathrm{Y}$ and $\mathrm{Ch}-\mathrm{Y}$, although the origin of the weak high-wavenumber band from Ch-Y remains unknown.

The room-temperature IR spectrum of the channel-based medium-pore zeolite ferrierite, where the $\mathrm{Ch}^{+}$ions are present predominantly as a trans conformer, gives one band around $3480 \mathrm{~cm}^{-1}$. This band continuously shifts to $c a .3570 \mathrm{~cm}^{-1}$ with increasing the measurement temperature to $400^{\circ} \mathrm{C}$. In contrast, the spectrum of the channel-based small-pore zeolite phillipsite shows two $\mathrm{OH}$ stretching bands around 3450 and $3580 \mathrm{~cm}^{-1}$, the positions of which are almost insensitive to the IR measurement temperature. Thus, while a similar interpretation to that applied to the spectrum of levyne can be made to the $\mathrm{OH}$ stretching bands from phillipsite, the room-temperature IR spectrum of EU-12 containing trans $\mathrm{Ch}^{+}$ions only is characterized by one broad band around $3490 \mathrm{~cm}^{-1}$. Since this band position is similar to the value $\left(c a .3470 \mathrm{~cm}^{-1}\right)$ of the lowerwavenumber $\mathrm{OH}$ stretching band observed for the room temperature IR spectrum of levyne, it appears that the position of the $\mathrm{OH}$ stretching vibration mode of intrazeolitic $\mathrm{Ch}^{+}$ions is influenced by the interactions with the zeolite host rather than by the type of conformation.

The most important finding from Fig. 3 is that although IR measurements were performed at $150{ }^{\circ} \mathrm{C}$, there are no noticeable changes in the number, position and shape of the $\mathrm{OH}$ stretching band of $\mathrm{Ch}^{+}$ions in each zeolite. Given that all zeolites studied here were synthesized at $100-150{ }^{\circ} \mathrm{C}$ (Table S1, ESI $\dagger$ ), therefore, their host-guest interactions were maintained in a manner different from one another even at the crystallization temperature. However, the thermal energy at $150{ }^{\circ} \mathrm{C}$ is only $3.5 \mathrm{~kJ} \mathrm{~mol}^{-1}$ that is fairly lower than the difference $\left(\geq 18 \mathrm{~kJ} \mathrm{~mol}^{-1}\right)$ between the gas-phase energy levels of gauche $\mathrm{Ch}^{+}$and its trans or trans ${ }^{\prime}$ form. ${ }^{17}$ This implies that the interchange of the former conformer to the latter one is thermodynamically unfavorable to take place under zeolite synthesis conditions employed here. If such is the case, $\mathrm{Ch}^{+}$would exist most commonly as the gauche conformer at the nucleation stage, thus being entrapped as the same or similar form within the void space of the developing zeolite host structure. As characterized by Raman spectroscopy, however, the OSDA molecules in ferrierite, phillipsite and EU-12 are predominantly or exclusively in the trans conformation, suggesting that the conformation of $\mathrm{Ch}^{+}$is a critical phase selectivity factor in zeolite syntheses. In this respect, its conformation may have an important kinetic role as an OSDA, but not as a pore-filling agent.

To gain insights into the structure-directing effects of $\mathrm{Ch}^{+}$ conformation on the phase selectivity of the crystallization, we performed relative energy calculations on its gauche, trans and trans' $^{\prime}$ conformers embedded in five different representative zeolite structures, but in seven different OSDA locations (i.e., 96T Y supercage, 48T Y sod cage, $78 \mathrm{~T}$ ferrierite channel intersection, 76T ferrierite fer cage, 64T phillipsite, 88T EU-12, and $60 \mathrm{~T}$ levyne models). Here we did not carry out energy calculations on the $\mathrm{Ch}^{+}$conformers in UZM-4, UZM-22 and offretite, owing to the lack of information on the reliable OSDA locations in these channel-based large-pore zeolites. According to the TGA/DTA results, each supercage in $\mathrm{Ch}-\mathrm{Y}$ with $\mathrm{Si} / \mathrm{Al}=2.6$ contains $c a .2 .6 \mathrm{Ch}^{+}$ions on average. Thus, we assumed that the Y supercage can accommodate up to three $\mathrm{Ch}^{+}$ions. We first calculated the energies of trans and trans ${ }^{\prime} \mathrm{Ch}^{+}$ions relative to the gauche conformer in the free state, using their optimized geometries. The energies calculated relative to the 'free' gauche conformer were 23 and $27 \mathrm{~kJ} \mathrm{~mol}^{-1}$, respectively. These values are a little higher than those (18 and $23 \mathrm{~kJ} \mathrm{~mol}^{-1}$, respectively) reported by Ashworth et al., ${ }^{17}$ which can be attributed to differences in the method by which the respective sets of energies have been calculated. But note that they are still significantly greater than the thermal energy $\left(3.5 \mathrm{~kJ} \mathrm{~mol}^{-1}\right)$ at $150{ }^{\circ} \mathrm{C}$. When the optimized structures of three representative $\mathrm{Ch}^{+}$conformers were introduced into each theoretical model described above, on the other hand, their $\mathrm{N}-\mathrm{C}-\mathrm{C}-\mathrm{O}$ and $\mathrm{C}-\mathrm{C}-\mathrm{O}-$ $\mathrm{H}$ dihedral angles were found to slightly deviate from the torsion angles of free gauche (60 and $180^{\circ}$ ), trans (180 and $180^{\circ}$ ) and trans ${ }^{\prime}\left(180\right.$ and $90^{\circ}$ ) conformations, probably due to the steric hindrance between the ammonium head and $\mathrm{OH}$ groups in $\mathrm{Ch}^{+}$, as well as that with the zeolite framework.

Table 2 lists the relative energies of the three different $\mathrm{Ch}^{+}$ conformers in various zeolite models. It is clear that the energetically preferred conformation differs according to the structure type of zeolite hosts. For example, gauche $\mathrm{Ch}^{+}$is more stable in the Y supercage and levyne by ca. 60 and $28 \mathrm{~kJ} \mathrm{~mol}^{-1}$ than the trans conformer, respectively. With increasing the number of $\mathrm{Ch}^{+}$ions in the $\mathrm{Y}$ supercage to three, in addition, the difference in the relative energies of gauche and trans or trans $\mathrm{Ch}^{+}$ increases. When $\mathrm{Ch}^{+}$is embedded in the $\mathrm{Y}$ sod cage, ferrierite 
Table 2 Relative, deformation, interaction and total stabilization energies of three representative $\mathrm{Ch}^{+}$conformers embedded in various zeolite structures calculated at the $\omega \mathrm{B} 97 \mathrm{XD} / 6-31 \mathrm{G}(\mathrm{d}, \mathrm{p})$ level of theory

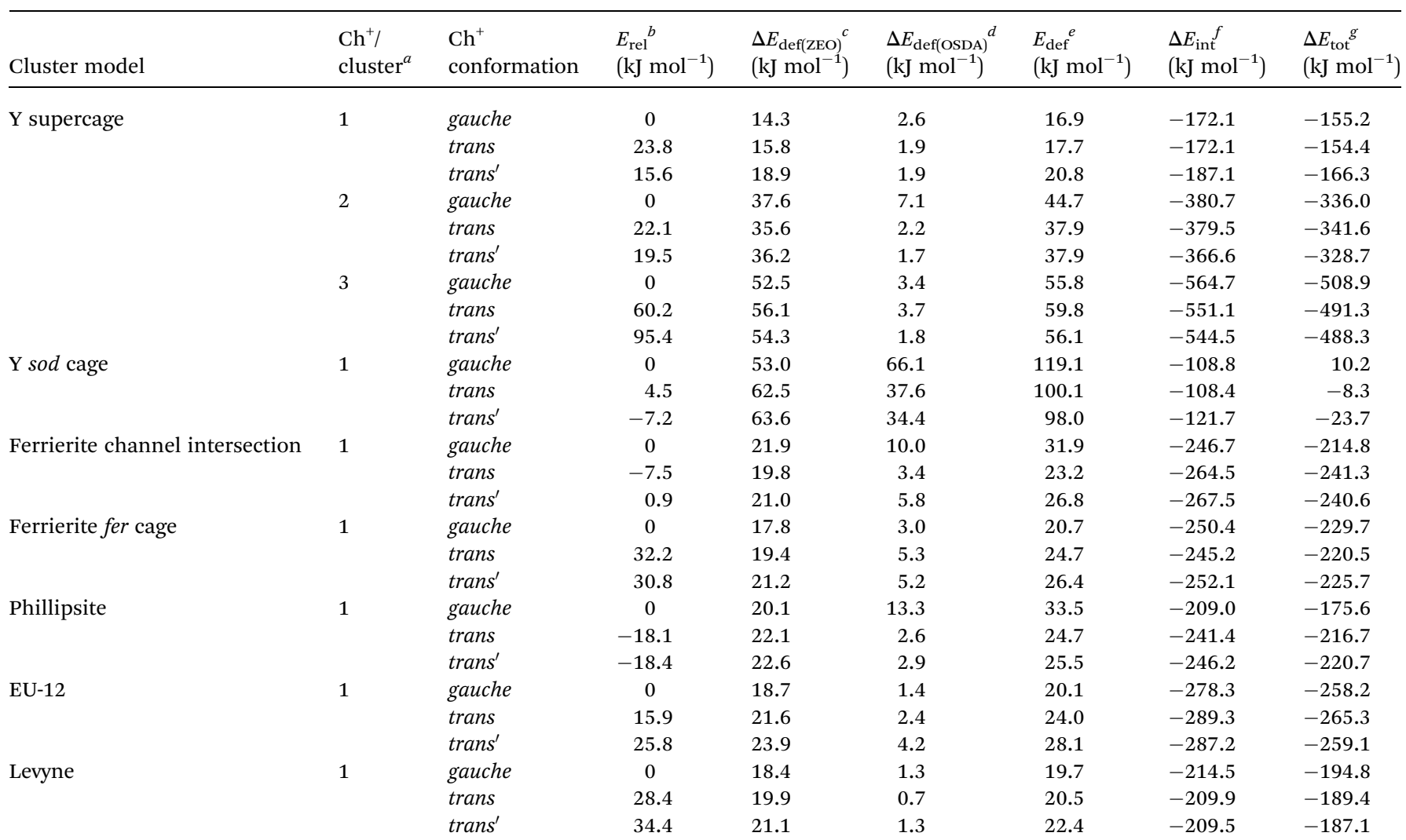

${ }^{a}$ The number of $\mathrm{Ch}^{+}$ions occluded in a given cluster model. The structures of the most stable $\mathrm{Ch}^{+}$conformer in each cluster model can be found in Fig. $4 .{ }^{b} E_{\text {rel }}=E_{\text {OSDA/ZEO }}-E_{\text {gauche } / \text { ZEO }}{ }^{c} \Delta E_{\text {def(ZEO) }}=E_{(\mathrm{ZEO})}^{c}-E_{(\mathrm{ZEO}) \cdot} \cdot{ }^{d} \Delta E_{\mathrm{def}(\mathrm{OSDA})}=E_{(\mathrm{OSDA})}^{\mathrm{c}}-E_{(\mathrm{OSDA}) \cdot} \cdot{ }^{e} E_{\mathrm{def}}=\Delta E_{\mathrm{def}(\mathrm{ZEO})}+\Delta E_{\mathrm{def}(\mathrm{OSDA})} \cdot{ }^{f} \Delta E_{\mathrm{int}}=E_{\mathrm{OSDA} /}$ ZEO $-E_{(\mathrm{ZEO})}^{\mathrm{c}}-E_{(\mathrm{OSDA})}^{\mathrm{c}}{ }^{g} \Delta E_{\mathrm{tot}}=E_{\text {def }}+\Delta E_{\text {int }} \cdot$

channel intersection and phillipsite, however, trans or trans' $\mathrm{Ch}^{+}$has a lower relative energy $\left(-7.2,-7.5\right.$ and $-18.4 \mathrm{~kJ} \mathrm{~mol}^{-1}$, respectively) than gauche $\mathrm{Ch}^{+}$, which correlates well with the Raman results in Fig. 2. An unexpected result from Table 2 is that gauche $\mathrm{Ch}^{+}$is considerably more stable (>30 and > $15 \mathrm{~kJ} \mathrm{~mol}^{-1}$, respectively) in the ferrierite fer cage and EU-12 than trans or trans' $\mathrm{Ch}^{+}$, although the OSDA molecules dominantly or exclusively present in these zeolites were characterized to adopt a trans conformation (Fig. 2). Moreover, the relative energy difference $\left(11.7 \mathrm{~kJ} \mathrm{~mol}^{-1}\right)$ between the trans and trans' $\mathrm{Ch}^{+}$conformers in the $\mathrm{Y}$ sod cage was calculated to be larger than that $\left(7.2 \mathrm{~kJ} \mathrm{~mol}^{-1}\right)$ between the gauche and trans $\mathrm{Ch}^{+}$ conformers in the same small cage, which is opposite to the trend found in the other zeolite models. These results inspired us to focus on the total stabilization energies of the three different $\mathrm{Ch}^{+}$conformers in each zeolite structure.

As shown in Table 2, the conformer with the lowest total stabilization energy in a given zeolite model was found to be always identical to that experimentally identified to dominantly or exclusively exist in the corresponding zeolite, which is now also the case for $\mathrm{Ch}^{+}$in EU-12. The total stabilization energy of the trans conformer in this channel-based zeolite is lower by $7.1 \mathrm{~kJ} \mathrm{~mol}^{-1}$ than that of the gauche one, because the intermolecular interaction energy of trans $\mathrm{Ch}^{+}$with the EU-12 framework is lower by $11.0 \mathrm{~kJ} \mathrm{~mol}^{-1}$ than that of gauche $\mathrm{Ch}^{+}$and thus offsets the difference $\left(3.9 \mathrm{~kJ} \mathrm{~mol}^{-1}\right)$ in their total deformation energies. A similar trend was observed for the gauche and trans $\mathrm{Ch}^{+}$ions in the Y sod cage, mainly due to the large difference in the deformation energies of the two conformers. When $\mathrm{Ch}^{+}$is embedded in the ferrierite fer cage, on the other hand, the difference in the total stabilization energy was calculated to be only $4.0 \mathrm{~kJ} \mathrm{~mol}^{-1}$, regardless of its conformation type. Thus, the gauche conformer which was experimentally confirmed to exist in ferrierite (Table 1) appears to be mainly located within the fer cage. Table 2 also shows that the difference ( 15.4 vs. $<6.2 \mathrm{~kJ} \mathrm{~mol}^{-1}$ ) in the total stabilization energies of trans and trans ${ }^{\prime} \mathrm{Ch}^{+}$conformers is still larger in the $\mathrm{Y}$ sod cage than in the other six zeolite models. It should be noted here that the intermolecular interaction energy $\left(-121.7\right.$ vs. $\left.-108.4 \mathrm{~kJ} \mathrm{~mol}^{-1}\right)$ of trans $^{\prime} \mathrm{Ch}^{+}$with the $\mathrm{Y}$ sod cage is much lower than that of trans $\mathrm{Ch}^{+}$, although a similar strain was imposed on both $\mathrm{Ch}^{+}$conformers. This strongly suggests that even small differences in the OSDA conformation can greatly affect the phase selectivity of the crystallization. All these calculation results led us to believe that the $\mathrm{Ch}^{+}$ions encapsulated within the inorganic-organic structures should selfassemble during zeolite nucleation and already adopt a very narrow range of conformations similar to that which they have in the zeolite product. 
It has been repeatedly shown that OSDAs with a high degree of flexibility, as well as rigid and bulky OSDAs, direct the synthesis of a number of different zeolite structures, depending on the type and concentration of ISDAs such as alkali metal cations, $\mathrm{OH}^{-}$or $\mathrm{F}^{-}$anions and/or heteroatoms other than $\mathrm{Si}$ in the synthesis mixture, as well as on the crystallization time and temperature..$^{\mathbf{4 1 8 , 1 9}}$ Since the type and concentration of ISDAs, as well as the water concentration, in $\mathrm{Ch}^{+}$-containing zeolite synthesis mixtures used here are different from one another (Table S1, ESI $\dagger$ ), the most abundant type of $\mathrm{Ch}^{+}$conformations under synthesis conditions may be different from one another. The fact that the relative energies of various $\mathrm{Ch}^{+}$conformers within various zeolite structures calculated from a thermodynamic point of view are not always consistent with the experimental results suggests the 'instantaneous capture' of specific types of OSDA conformations under zeolite synthesis conditions. This may play an important 'kinetic' role in determining the structure type of zeolites during the nucleation process, because the absolute value range $\left(7-60 \mathrm{~kJ} \mathrm{~mol}^{-1}\right)$ of differences in the relative energies of intrazeolitc $\mathrm{Ch}^{+}$conformers (Table 2) is significantly larger than the thermal energy $\left(\leq 3.5 \mathrm{~kJ} \mathrm{~mol}^{-1}\right)$ available at the synthesis temperatures of zeolites studied here.

Finally, to examine the effects of OSDA hydrophobicity $(\mathrm{OH}$ vs. $\mathrm{CH}_{3}$ ) on the phase selectivity of the crystallization, we replaced $\mathrm{Ch}^{+}$ions in some synthesis mixtures with the equimolar amount of propyltrimethylammonium (PTMA ${ }^{+}$) ions, whose shape and size are quite similar to those of $\mathrm{Ch}^{+}$ions, and carried out zeolite syntheses while keeping the other synthesis parameters constant. When we used PTMA ${ }^{+}$under the conditions where the formation of levyne, EU-12 and phillipsite proved to be highly reproducible, the phases we obtained were analcime, mordenite and a mixture of phillipsite and mordenite, respectively. Therefore, it appears that OSDA hydrophobicity can have a great influence on the phase selectivity, as well as on the rate of crystallization, ${ }^{\mathbf{2 8}}$ although further study is necessary to more precisely understand this effect.

\section{Conclusions}

The relationship between the conformation of $\mathrm{Ch}^{+}$ions used as an OSDA in zeolite synthesis and the framework structure of the series of resulting zeolite hosts (i.e., Y, UZM-4, UZM-22, offretite, ferrierite, phillipsite, EU-12 and levyne) has been studied by elemental and thermal analyses, Raman, ${ }^{1} \mathrm{H}^{-13} \mathrm{C}$ CP MAS NMR, variable-temperature IR and theoretical calculations. The overall experimental results of this study reveal that the conformation of $\mathrm{Ch}^{+}$varies not only with the structure type of zeolite hosts but also with the intrazeolitic location. The pure-silica model-based theoretical calculations on the gauche, trans and trans' $^{\prime}$ conformers of this asymmetric OSDA in various zeolite structures show that a specific $\mathrm{Ch}^{+}$conformer, which was experimentally identified to be dominantly or exclusively present in a given zeolite, gives a lower intermolecular interaction energy, one of the main driving forces for self-assembly processes like zeolite crystallization. Therefore, particular types of OSDA conformations may be kinetically captured or "frozen out" under zeolite synthesis conditions, acting as a phase selectivity factor during zeolite nucleation and thus to play a structure-directing role rather than a pore-filling one. This explains why the use of flexible OSDAs in zeolite synthesis has been of major importance and needs to continue in the search for zeolitic materials with unprecedented framework structures.

\section{Conflicts of interest}

There are no conflicts to declare.

\section{Acknowledgements}

This work was supported by the National Creative Research Initiative Program (2012R1A3A2048833) through the National Research Foundation of Korea.

\section{Notes and references}

1 R. M. Barrer and P. J. Denny, J. Chem. Soc., 1961, 971.

2 R. Szostak, Handbook of Molecular Sieves, Van Nostrand Reinhold, New York, 1992.

3 M. A. Camblor and S. B. Hong, in Porous Materials, ed. D. W. Bruce, D. O'Hare and R. I. Walton, Wiley, Chichester, 2011, p. 265.

4 M. Moliner, F. Rey and A. Corma, Angew. Chem., Int. Ed., 2013, 52, 13880.

5 J. Li, A. Corma and J. Yu, Chem. Soc. Rev., 2015, 44, 7112.

6 S. B. Hong, M. A. Camblor and M. E. Davis, J. Am. Chem. Soc., 1997, 119, 761.

7 M. G. O'Brien, A. M. Beale, C. R. A. Catlow and B. M. Weckhuysen, J. Am. Chem. Soc., 2006, 128, 11744.

8 J. E. Schmidt, D. Fu, M. W. Deem and B. M. Weckhuysen, Angew. Chem., Int. Ed., 2016, 55, 16044.

9 M. A. Miller, J. G. Moscoso, S. C. Koster, M. G. Gatter and G. J. Lewis, Stud. Surf. Sci. Catal., 2007, 170, 347.

10 Y. Lee, M. B. Park, P. S. Kim, A. Vicente, C. Fernandez, I.-S. Nam and S. B. Hong, ACS Catal., 2013, 3, 617.

11 J. Bae, J. Cho, J. H. Lee, S. M. Seo and S. B. Hong, Angew. Chem., Int. Ed., 2016, 55, 7369.

12 T. Inoue, M. Itakura, H. Jon, Y. Oumi, A. Takahashi, T. Fujitani and T. Sano, Microporous Mesoporous Mater., 2009, 122, 149.

13 J. Hjortás and H. Sørum, Acta Crystallogr., 1971, B27, 1320.

14 P. Partington, J. Feeney and A. S. V. Burgen, Mol. Pharmacol., 1972, 8, 269.

15 Y. Terui, M. Ueyama, S. Satoh and K. Tori, Tetrahedron, 1974, 30, 1465.

16 L. Tanzi, P. Benassi, M. Nardone and F. Ramondo, J. Phys. Chem. A, 2014, 118, 12229.

17 C. R. Ashworth, R. P. Matthews, T. Welton and P. A. Hunt, Phys. Chem. Chem. Phys., 2016, 18, 18145.

18 B. Han, S.-H. Lee, C.-H. Shin, P. A. Cox and S. B. Hong, Chem. Mater., 2005, 17, 477.

19 B. Han, C.-H. Shin, P. A. Cox and S. B. Hong, J. Phys. Chem. B, 2006, 110, 8188. 
20 C. Baerlocher and L. B. McCusker, Database of Zeolite Structures, http://www.iza-structure.org/databases/, accessed July 18, 2018.

21 M. J. Frisch, et al., Gaussian 09, Revision C.01, Gaussian, Inc., Wallingford, CT, 2010.

22 H. Akutsu, Biochemistry, 1981, 20, 7359.

23 H. Akutsu, Y. Suezaki, W. Yoshikawa and Y. Kyogoku, Biochim. Biophys. Acta, 1986, 854, 213.

24 S. B. Hong, Microporous Mater., 1995, 4, 309.
25 H. Koller, R. F. Lobo, S. L. Burkett and M. E. Davis, J. Phys. Chem., 1995, 99, 12588.

26 D. C. Apperley, M. J. Hudson, M. T. J. Keene and J. A. Knowles, J. Mater. Chem., 1995, 5, 577.

27 G. Socrates, Infrared and Raman Characteristic Group Frequencies: Tables and Charts, J. Wiley and Sons, Chichester, 2001.

28 A. A. V. Goretsky, L. W. Berk, S. I. Zones and M. E. Davis, Microporous Mesoporous Mater., 1999, 28, 387. 